\title{
Language Learning Strategy Preferences and Levels of Willingness to Communicate by Iranian EFL Learners
}

\section{Seyedeh Khadijeh Najafi ${ }^{1 *}$, Ali Panah Dehghani ${ }^{1}$}

${ }^{1}$ Department of English, Kazerun Branch, Islamic Azad University, Kazerun, Iran

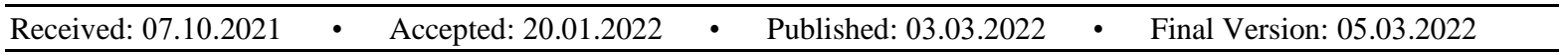

\begin{abstract}
The present study aims at investigating the relationship between Iranian EFL learners' levels of willingness to communicate (WTC) and their preferences of language learning strategies. To achieve this goal, a quantitative study was carried out with 46 Iranian EFL learners majoring in English translation. The participants'WTC levels were determined through willingness to communicate (WTC) questionnaire developed by McCroskey and Richmond (2013). Oxford's (1990) Strategy Inventory for Language Learners (SILL) was also used as another instrument to investigate the participants' preferences of language learning strategy use. The participants were moderate strategy users. Metacognitive and cognitive strategies were found to be used strongly by the participants of the study. It was also found that the participants were moderate regarding their willingness to communicate. Furthermore, a significant correlation was found to exist between the two variables of the study. The findings of this study have implications for teachers, students, material developers as well as course designers
\end{abstract}

Keywords: Willingness to communicate (WTC), language learning strategies (LLS), undergraduate EFL learners

\section{Introduction}

It is actually evident that communicative approach changed language teaching domain to a great extent; automatically, more scholars have put emphasis on the value and significance of communication in their language learning practices and concentrate on different constructs which affect communicative abilities of the learners. Among these, the construct of Willingness to Communicate (WTC)is the focus of this study. This construct was first introduced by McCroskey and Baer in 1985; since then researchers have shown interest in this construct and started to investigate how WTC affect or is influenced by various aspects of language. Furthermore, taking affective factors in psychology of language learning into consideration, it is obvious that motivating learners to communicate provide an active language learning classroom. Hence, usingL2 actively in language learning settings leads to the aforementioned construct which is called willingness to communicate. Learners with a high level of willingness to communicate tend to be very active and engaged in language learning activities and this leads to taking much more advantages of the presented materials in the class; this is proved in reviewing the related literature. (e.g.,Rahbar,Suzani, and Sajadi, 2016;Bergil, 2016; Fahim and Dhamotharan, 2016; Aliakbari, Kamangar, and Khany, 2016). Hence, it is of utmost importance to pinpoint the factors that influence WTC of language learners as in this way, they use language in a more communicative way. 
In order to communicate effectively, individuals also need to express what they mean in a number of ways in their everyday communication. According to Richards, Platt \& Platt (1992) learners employ a wide range of language strategies to achieve this goal (Richards, Platt \& Platt, 1992). They argued that "learning strategies are intentional behavior and thoughts that learners make use of during learning in order to better help understand, learn or remember new information "(p.209).

Learning strategies are considered as special manners of information processing that could enhance comprehension, learning, or retention of information. A look at the related literature shows that different studies have focused on use of language learning strategies and the ones that are employed by language learners (e.g., Dawadi, 2017; Alhaysony, 2017; Chamot,2004). The strategies that L2 learners employ in the process of learning the target language have been categorized by many professional experts in the area of foreign/second language learning. However, in the present research, Oxford's (1990) taxonomy of language learning strategies is applied. Oxford (1990) provided one of the most applicable definitions that has been cited most recurrently in the literature of L2 learning strategies, "specific actions taken by the learner to make learning easier, faster, more enjoyable, more self-directed, more effective, and more transferable to new situations" (P.8). This definition is a reflection of what language learners intend to do and the specific actions they can take. Correspondingly, she includes how context plays a vital role in the process of language learning Predominantly

Many researchers have recently investigated WTC and language learning strategies (Rahbar,Suzani, and Sajadi, 2016; Aliakbari, Kamangar, and Khany, 2016; Khajavy, Ghonsooly and HosseiniFatemi, 2016; Chen, 2015; Zarei, and Gilanian, 2015; Valadi, Rezaee, and Kogani, 2015; Yousefi, and Kasaian, 2014;Ahmadi and Mahmoodi, 2012; Kunasaraphan, 2015;Mashhady, and Fallah, 2014; Ghavamnia, Kassaian, and Dabaghi, 2011), However, it seems a gap exists in the relationship between Iranian EFL learners' levels of willingness to communicate (WTC) and their preferences of language learning strategies. Thus, the present study aims at filling the aforementioned gap. The findings of the present study are expected to shed some lights to teachers, learners, material developers, and curriculum developers. Teachers would enhance their students WTC in order to communicate more in language classes; also guiding them to improve their use of language learning strategies by familiarizing them with the appropriate use and automatically this will help learners to be more successful in language learning. Syllabus designers and policy makers can also arrange the materials in a way to improve WTC of the learners through enticing them to use proper and more language learning strategies in their process of language learning. To this end, the present study was an attempt to answer the following research questions:

1. What are Iranian EFL learners' preferences of language learning strategies?

2. What are WTC levels of Iranian EFL learners?

3.Whatis the relationship between Iranian WTC levels and their preferences of language learning strategies?

of the learners through enticing them to use proper and more language learning strategies in their process of language learning. To this end, the present study was an attempt to answer the following research questions:

1. What are Iranian EFL learners' preferences of language learning strategies?

2. What are WTC levels of Iranian EFL learners?

3.Whatis the relationship between Iranian WTC levels and their preferences of language learning strategies?

\section{Review of the Related Literature}

Various pieces of research have been carried out with concentration on the role of interaction and communication in improving language learning. Focus on communication came into vogue with the emergence of communicative language teaching during 1970s. Willingness to communicate (WTC) in 
a second language which was raised by MacIntyreet al. (1998) initiate with the concept of learners' reluctance to speak in a second language. WTC is actually a process through which language learners decide whether or not to choose to apply second language in their speech. And the model of WTC which was introduced by MacIntyreet al.'s (1998) model clustered linguistic, social psychological and communicative variables as factors contributing to WTC in a second language. Accordingly, a growing number of investigations (e.g.,Alemi, Tajeddin, and Mesbah, 2013; Cao and Philip 2006)concentrate on the relationship between L2 learners' willingness to communicate and various variables that may impact language learning.

A quick look at the literature indicates that the most inclusive taxonomy of language learning strategies is proposed by Oxford (1990). Oxford divided language-learning strategies into two main categories, namely direct and indirect strategies, which are in turn subdivided into six categories. The classes in direct strategies, which include the new language directly, are memory strategies, cognitive strategies and compensation strategies. On the other hand, indirect strategies involve metacognitive, affective and social strategies. Actually, this effort provided a foundation for an instrument, namely the Strategy Inventory for Language Learning (SILL), developed to get information about strategy use of language learners in learning a second/foreign language. Although Oxford's inventory is defined plainly, she emphasizes that the current understanding of learning strategies is still in its early stages and, in her exact words (Oxford 1990, p. 16), "it is only a proposal to be tested through practical classroom use and through research".

Through reviewing the related literature, it is evident that various lines of research have been performed on the construct of WTC and its relationship with other variables that affect language learning. (e.g., Rahbar, Suzani and Sajadi, 2016; Bergil,2016; Fahim, and Dhamotharan, 2016; Aliakbari, Kamangar, and Khany, 2016).). Also, there were different pieces of research on language learning strategies and other variables. Major findings and arguments of past studies on language learning strategies in ESL/EFL learning can be reported as follows: Language learning strategies use varies according to different educational and cultural backgrounds (Ersözlü, 2010; Li, 2010; Yang, 1999). Gender differences in employing learning strategies can be observed (Ersözlü, 2010; Yan, Chye, Lin and Ying, 2010; Zare, 2010). More proficient language learners employ language learning strategies more frequently (Griffiths, 2003; Sheorey, 1999; Tuncer, 2009). Language learners are more likely to employ metacognitive and compensation strategies than affective strategies (Chen, 2009; Hong-Nam and Leavell, 2006; Hajhashemi, Ghombavani, and Amirkhiz (2011); Y1lmaz, 2010). Social strategies are beneficial in improving learners' proficiency in the target language and developing their intercultural communication (Griffiths, 2003; Sheorey, 1999). Bilingual L2 learners employ languagelearning strategies more than monolinguals (Tuncer, 2009). However, there were very few studies concerning the two main variables of the current study. To mention one as one of the rare example, Aycan (2017) examined the relationship between EFL learners' language learning strategy use, willingness to communicate, and L2 achievement and he found that by providing the learners with strategy training and helping them to use more strategies, WTC levels of the learners can be increased. Furthermore, he added that WTC and language learning strategies affect each other. However, they do not lead to increased L2 achievement. In another study, Mirsane and Khabiri (2016) investigated that strategy instruction can improve WTC of learners. The researchers of the study found those learners who seemed more eager and willing to communicate, apply different and more language learning strategies in their communication. Also Jamaleddin (2015) examined the relationship between socioaffective strategies and WTC and he claimed that there is a positive and strong relationship between these two variables.

The present study, however, was carried out to investigate the preferences of language learning strategies(namely both direct and indirect strategies including metacognitive, cognitive, social, 
affective, memory as well as compensation strategies)of Iranian EFL learners and their levels of willingness to communicate (WTC).Although many pieces of research were conducted to investigate strategy use and its preferences by language learners on one side and WTC of language learners on the other, the aforementioned studies were performed separately. Therefore, the current study was carried out to investigate preferences of language learning strategies with regard to the WTC levels of the EFL learners in an Iranian context.

\section{Method}

The participants of the study, instruments, data collection procedures as well as data analysis are dealt with in this section.

\subsection{Participants}

The participants of the current study were 46 undergraduate university students majoring in English translation at some of the Islamic Azad University branches. They were selected based on convenience sampling method for manageability reasons as well as availability. In terms of age, they were within the age range of 18 to 31 and included both male $(\mathrm{N}=12)$ and female $(\mathrm{N}=34)$ participants.

\subsection{Instruments and Design}

The present study employed a quantitative research design and the instruments were two questionnaires including the strategy inventory for language learning (SILL) designed by Oxford (1990) and a WTC questionnaire designed by McCroskey and Richmond (2013).

\subsubsection{Oxford's Strategy Inventory for Language Learners (1990)}

The most inclusive taxonomy of language learning strategies and the most widely employed strategy scale has been proposed by Oxford (1990). Oxford developed the SILL to measure language learning strategies for ESL and EFL learners (Version 7.0). The SILL consists of 50 items in the two dichotomous constructs of direct and indirect learning strategies, which is shown in the following Table.

Table 1. Oxford (1990) Strategy Inventory for Language Learning (SILL)

\begin{tabular}{rll}
\hline Direct & Memory & 9 items \\
strategies & Cognitive & 14 items \\
$\mathbf{2 9}$ items & Compensation & 6 items \\
\hline Indirect & Metacognitive & 9 items \\
strategies & Affective & 6 items \\
$\mathbf{2 1}$ items & Social & 6 items \\
\hline
\end{tabular}

In administering the SILL, respondents were asked to reflect on their use of language learning strategies in five-point Likert-scale items from "(1) never or almost never true of me" to "(5) always or almost always true of me." This questionnaire has been widely checked for its reliability and validity in multiple ways (Oxford, 1996). For example, Oxford and Nyikos (1989) found Cronbach's Alpha of 0.96 for SILL. Oxford and Burry-Stock (1995) established its predictive criterion-validity using its correlative relationship with language performance measures like course grades and proficiency ratings.

\subsubsection{McCroskey and Richmond WTC Questionnaire (2013)}

The Willingness to Communicate Scale (WTC) which was used in the present study was designed by McCroskey and Richmord, (2013). This questionnaire is a 20-item, probability estimate scale. It is actually designed as a direct measure of the respondent's predisposition with regard to the way they avoid or approach the initiation of communication. The face validity of the questionnaire is strong, and 
the results of extensive research confirmed the predictive validity of the instrument. Also, the Alpha reliability estimates for this instrument have ranged from .85 to above .90 . It should be mentioned that among the 20 items of the instrument, only twelve items generate a total score, four context-type scores, and three receiver-type scores and the remaining eight items are used to distract attention from the scored items.

\subsection{Procedures for Data Collection and Data Analysis}

The present study coincides with the outbreak of corona virus (COVID-19) across the country. Thus, to protect the safety of the participants and to consider the international medical and health protocols, the researcher had to consider the individual and social distancing measurements and avoid gathering all participants in groups. Consequently, the two questionnaires were distributed online to the participants. In order to collect the related data, the aforementioned tests were administered by the researchers of the study as well as two other colleagues on behalf of the researchers in online classes. Then the questionnaires were collected and the data was analyzed.

In order to analyze the related data, Statistical Package for Social Sciences (SPSS)version 26 was used. The data was analyzed quantitatively, and inferential statistical procedures were applied. Onesample Kolmogorov-Smirnov Test was run to check the normality and to determine whether to use parametric or nonparametric tests in the study; since the data was not normal, Spearman correlation was run.

\section{Findings and Results}

\subsection{Participants' Preferences of Language Learning Strategies}

In order to measure language learning strategies for EFL learners, Oxford (1990) strategy Inventory for Language Learning (SILL) were employed. To analyze the data in regard with Oxford's (1990) Strategy Inventory for Language Learning (SILL), the mean score was calculated. According to the criteria of mean (Oxford, 1990), a mean score equal or above 3.50 was interpreted as strong strategy users, $(3.50 \leq \mathrm{M} \leq 5.00=$ strong); a mean score equal or above 2.50 but below 3.50 was interpreted as moderate strategy users $(2.50 \leq \mathrm{M}<3.50=$ moderate $)$, and a mean score below 2.50 was considered as weak strategy users $(\mathrm{M}<2.50=$ weak). Percentages, means, and standard deviations were also used to analyze these statements. After analyzing the data, the preferences of language learning strategies were determined.

Table 2. Preferences of language learning strategies

\begin{tabular}{|c|c|c|c|c|c|c|c|c|}
\hline & $\mathbf{N}$ & & Mean & $\begin{array}{c}\text { Media } \\
\mathbf{n} \\
\end{array}$ & Mode & $\begin{array}{c}\text { St.d } \\
\text { Deviation } \\
\end{array}$ & Min. & $\begin{array}{l}\text { Max } \\
. \\
\end{array}$ \\
\hline Strategies & $\begin{array}{l}\text { Vali } \\
\text { d }\end{array}$ & $\begin{array}{l}\text { Missin } \\
\mathrm{g}\end{array}$ & & & & & & \\
\hline Compensation & 46 & 0 & $\begin{array}{l}3.072 \\
5\end{array}$ & $\begin{array}{l}3.000 \\
0\end{array}$ & 2.67 & $\begin{array}{l}.6718 \\
8\end{array}$ & $3^{1.8}$ & 4.33 \\
\hline Social & 46 & 0 & $\begin{array}{l}3.210 \\
1\end{array}$ & $\begin{array}{l}3.166 \\
7\end{array}$ & $\begin{array}{l}2.33 \\
\mathrm{a}\end{array}$ & $\begin{array}{l}.8273 \\
4\end{array}$ & $\begin{array}{l}1.8 \\
3\end{array}$ & 4.83 \\
\hline Memory & 46 & 0 & $\begin{array}{l}3.350 \\
2\end{array}$ & $\begin{array}{l}3.500 \\
0\end{array}$ & 3.67 & $\begin{array}{l}.7344 \\
1\end{array}$ & $2^{1.2}$ & 4.44 \\
\hline Affective & 46 & 0 & $\begin{array}{l}3.452 \\
9\end{array}$ & $\begin{array}{l}3.833 \\
3\end{array}$ & 4.17 & $\begin{array}{l}.9051 \\
7\end{array}$ & $\begin{array}{l}1.6 \\
7\end{array}$ & 4.83 \\
\hline Cognitive & 46 & 0 & $\begin{array}{l}3.523 \\
3\end{array}$ & $\begin{array}{l}3.571 \\
4\end{array}$ & 3.57 & $\begin{array}{l}.5767 \\
7\end{array}$ & $\begin{array}{l}2.2 \\
1\end{array}$ & 4.43 \\
\hline $\mathrm{e}^{\text {Metacognitiv }}$ & 46 & 0 & $\begin{array}{l}3.872 \\
0\end{array}$ & $\begin{array}{l}3.944 \\
4\end{array}$ & 3.67 & $\begin{array}{l}.6719 \\
8\end{array}$ & $\begin{array}{l}1.7 \\
8\end{array}$ & 4.78 \\
\hline
\end{tabular}

a. Multiple modes exist. The smallest value is shown 
According to Table 2, the participants' preferences in different parts of the SILL were as follows: Metacognitive strategy with the mean score of 3.87 ranked as the most frequent strategy applied by the participants of the study; cognitive strategy with the mean score 3.52 ranked as the second frequent applicable strategy by the participants; According to the criteria of Oxford (1990), the participants of the study were strong in the use of metacognitive and cognitive strategies.

Moreover, affective strategy with the mean score 3.45 ranked as the third frequent applicable strategy. Memory strategy with the mean score of 3.35 ranked as the fourth frequent strategy, while social strategy with the mean score of 3.21 and compensation strategy with the mean score of 3.07 ranked as the least frequent strategies respectively. According to the criteria set by Oxford (1990), a mean score equal or above 2.50 but below 3.50 is interpreted as having a moderate degree of impact $(2.50 \leq \mathrm{M}<3.50=$ moderate $)$. Hence, the participants of the study used affective, memory, social and compensation strategies moderately.

\subsection{The Participants' Levels of willingness to communicate}

The data in regard with WTC were analyzed based on the guidelines presented by the designer of WTC questionnaire (McCroskey and Richmord, 2013). The WTC questionnaire included 20 situations in which a person might choose to communicate or not to communicate. The participants were required to indicate the percentage of times they would choose to communicate in each type of situation. The participants needed to indicate in the space at the left of the item what percent of the time they would choose to communicate. $(0=$ Never to $100=$ Always $)$. According to the measure provided by McCroskey and Richmord(2013), the mean percentages of total WTC $>82$ indicate high overall WTC, and $<52$ Low WTC. For the Group Discussion, scores for items 8, 15, \& 19 were added ,then divided by 3; for Meetings: scores for items 6,11, 17 were added, then divide by 3;for Interpersonal, scores for items 4, 9, 12 were added ; then divide by 3;for Public Speaking, scores for items 3, 14, 20 were added, then divide by 3; for Stranger: scores for items 3, 8, 12, 17 were added; then divide by 4; for Acquaintance, scores for items 4, 11, 15, 20 were added then divide by 4 and for Friend scores for items $6,9,14,19$ were added then divide by 4 .

In Table 3, the obtained mean score of the participants with regard to their willingness to communicate (WTC) is presented.

Table 3. The participants' performances on WTC

\begin{tabular}{cccc}
\hline Mean & Std. Deviation & Minimum & Maximum \\
67.47 & 23.74 & 11.67 & 95.83 \\
\hline
\end{tabular}

As it is shown, the overall mean percentage was 67.5 , meaning that the participants were moderate regarding their willingness to communicate.

Table 4. Descriptive statistics for different levels of WTC

\begin{tabular}{|c|c|c|c|c|c|}
\hline \multirow[b]{2}{*}{$\mathrm{Va}$} & & Frequency & percent & $\begin{array}{r}\text { Valid } \\
\text { percent }\end{array}$ & Cumulative percent \\
\hline & Low & 11 & 23.9 & 23.9 & 23.9 \\
\hline \multirow[t]{3}{*}{ lid } & Moderate & 17 & 37.0 & 37.0 & 60.9 \\
\hline & High & 18 & 39.1 & 39.1 & 100.0 \\
\hline & Total & 46 & 100.0 & 100.0 & \\
\hline
\end{tabular}

According to Table 4, among the 46 participants of the study, 11 were low overall (23.9\%), 17 were moderate overall (37\%) and $18(39.1 \%)$ were high overall with regard to their levels of willingness to communicate.

The males and females' performances on WTC levels were analyzed, using descriptive statistics, and the results are given below. 
56 Najafi et al.: Language Learning Strategy Preferences and Level of Willingness to Communicate by Iranian EFL Learners

Table 5. Males and females' performances on various levels of WTC

\begin{tabular}{ccccccc}
\hline Sex & & & $\begin{array}{c}\text { Frequen } \\
\text { cy }\end{array}$ & $\begin{array}{c}\text { Perce } \\
\text { nt }\end{array}$ & $\begin{array}{c}\text { Valid } \\
\text { Percent }\end{array}$ & Cumulative Percent \\
Male & Val & Low & 2 & 16.7 & 16.7 & 16.7 \\
& id & Moderate & 4 & 33.3 & 33.3 & 50.0 \\
& & High & 6 & 50.0 & 50.0 & 100.0 \\
& & Total & 12 & 100.0 & 100.0 & 26.5 \\
\hline \multirow{2}{*}{ Fem } & Val & Low & 9 & 26.5 & 26.5 & 64.7 \\
& id & Moderate & 13 & 38.2 & 38.2 & 100.0 \\
\hline
\end{tabular}

As shown in Table 5, among the 12 male participants of the study, $2(16.7 \%)$ were low overall, 4 $(33.3 \%)$ were moderate overall and $6(50 \%)$ were high overall, while among the female participants of the study, $9(26.5 \%)$ were low overall, $13(38.2 \%)$ were moderate and $12(35.3 \%)$ were high overall. The overall performances of the males and females' performances are depicted in Figure 2.

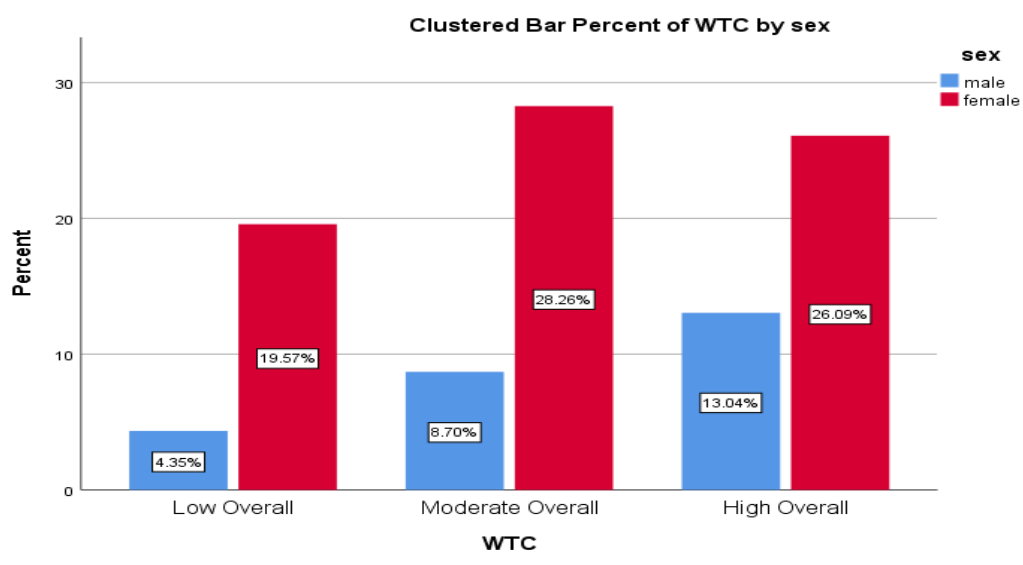

Figure 1. Descriptive statistics for gender and levels of WTC

\subsection{The relationship between preferences of language learning strategies and willingness to communicate}

To determine the correlation between SILL and WTC, Kolmogorov-Smirnov Test was firstly run to indicate the normality of the data. The results are given below:

Table 6. One-Sample Kolmogorov-Smirnov Test

\begin{tabular}{|c|c|c|c|}
\hline & & SIL & WTC \\
\hline $\mathrm{N}$ & & 46 & 46 \\
\hline \multirow[t]{4}{*}{ Normal Parameters ${ }^{\mathrm{a}, \mathrm{b}}$} & Mean & 3.413 & 67.4710 \\
\hline & & 5 & \\
\hline & Std. & .5217 & 23.74007 \\
\hline & Deviation & 0 & \\
\hline Extreme & Absolute & .103 & .139 \\
\hline \multirow[t]{2}{*}{ Differences } & Positive & .051 & .116 \\
\hline & Negative & -.103 & -.139 \\
\hline Test Statistic & & .103 & .139 \\
\hline Asymp. Sig. (2-tailed) & & $.200^{\mathrm{c}, \mathrm{d}}$ & $.026^{\mathrm{c}}$ \\
\hline
\end{tabular}


As shown in Table 6, one-sample Kolmogorov-Smirnov Test was run to check the normality and to determine whether to use parametric or nonparametric tests in the study; since the data was not normal, Spearman correlation was administered.

Table 7. Spearman correlation between SILL and WTC

\begin{tabular}{|c|c|c|c|c|}
\hline & & & SIL & WTC \\
\hline Spearman's & SI & Correlation & 1.000 & $.379^{* *}$ \\
\hline \multirow[t]{7}{*}{ rho } & $\mathrm{L}$ & Coefficient & & \\
\hline & & Sig. (2-tailed) & . & .009 \\
\hline & & $\mathrm{N}$ & 46 & 46 \\
\hline & W & Correlation & $.379^{* * *}$ & 1.000 \\
\hline & $\mathrm{TC}$ & Coefficient & & \\
\hline & & Sig. (2-tailed) & .009 & . \\
\hline & & $\mathrm{N}$ & 46 & 46 \\
\hline
\end{tabular}

** Correlation is significant at the 0.01 level (2-tailed).

According to Table 7, the relationship between the participants' willingness to communicate (as measured by McCroskey, and Richmond, 2013) and the language learning strategies (as measured by Strategy Inventory for language learning, SILL) was investigated using Spearman Correlation coefficient. The analysis of the results indicated that $\mathrm{p}=.009<.05$, so there is a significant relationship between willingness to communicate and the learning strategies of the participants of the study $(\mathrm{r}=$ $.379, \mathrm{p}=.009)$.

Table 8. Descriptive statistics for preferences of SILL and WTC

\begin{tabular}{|c|c|c|c|c|c|c|c|c|}
\hline WTC & SILL & valid & Mean & $\begin{array}{c}\text { Media } \\
\text { n }\end{array}$ & $\begin{array}{l}\text { Mo } \\
\text { de }\end{array}$ & Std. Deviation & $\begin{array}{l}\text { M } \\
\text { in }\end{array}$ & $\begin{array}{l}\text { Ma } \\
\text { x. }\end{array}$ \\
\hline \multirow[t]{12}{*}{ Low } & Memory & 11 & 2.82 & 2.5556 & 2.1 & .77198 & 1. & 4.2 \\
\hline & & & 83 & & $1^{\mathrm{a}}$ & & 78 & 2 \\
\hline & Cognitive & 11 & 3.22 & 3.2143 & 2.9 & .60171 & 2. & 4.2 \\
\hline & & & 73 & & $3^{a}$ & & 21 & 9 \\
\hline & Compensation & 11 & 3.03 & 2.8333 & 2.6 & .71031 & 1. & 4.1 \\
\hline & & & 03 & & 7 & & 83 & 7 \\
\hline & Metacognitive & 11 & 3.55 & 3.6667 & 3.6 & .72521 & 2. & 4.6 \\
\hline & & & 56 & & 7 & & 11 & 7 \\
\hline & Affective & 11 & 2.71 & 2.6667 & 1.6 & .66705 & 1. & 3.8 \\
\hline & & & 21 & & $7^{\mathrm{a}}$ & & 67 & 3 \\
\hline & Social & 11 & 3.19 & 2.8333 & 2.6 & .79519 & 2. & 4.5 \\
\hline & & & 70 & & $7^{\mathrm{a}}$ & & 17 & 0 \\
\hline \multirow[t]{12}{*}{ Moderat } & Memory & 17 & 3.40 & 3.4444 & 3.4 & .46637 & 2. & 4.4 \\
\hline & & & 52 & & $4^{\mathrm{a}}$ & & 33 & 4 \\
\hline & Cognitive & 17 & 3.55 & 3.5714 & 2.9 & .53840 & 2. & 4.3 \\
\hline & & & 46 & & $3^{\mathrm{a}}$ & & 71 & 6 \\
\hline & Compensation & 17 & 2.95 & 2.6667 & 2.3 & .63946 & 2. & 4.0 \\
\hline & & & 10 & & $3^{a}$ & & 17 & 0 \\
\hline & Metacognitive & 17 & 3.90 & 3.8889 & 3.6 & .49727 & 2. & 4.6 \\
\hline & & & 85 & & $7^{a}$ & & 89 & 7 \\
\hline & Affective & 17 & 3.55 & 4.0000 & 4.0 & 1.00854 & 1. & 4.8 \\
\hline & & & 88 & & 0 & & 67 & 3 \\
\hline & Social & 17 & 3.04 & 2.6667 & 4.5 & .98560 & 1. & 4.5 \\
\hline & & & 90 & & 0 & & 83 & 0 \\
\hline \multirow[t]{6}{*}{ High } & Memory & 18 & 3.61 & 3.7778 & 4.2 & .78588 & 1. & 4.4 \\
\hline & & & 73 & & 2 & & 22 & 4 \\
\hline & Cognitive & 18 & 3.67 & 3.8571 & 3.8 & .55934 & 2. & 4.4 \\
\hline & & & 46 & & 6 & & 21 & 3 \\
\hline & Compensation & 18 & 3.21 & 3.2500 & 2.6 & .69028 & 1. & 4.3 \\
\hline & & & 30 & & $7^{\mathrm{a}}$ & & 83 & 3 \\
\hline
\end{tabular}


58 Najafi et al.: Language Learning Strategy Preferences and Level of Willingness to Communicate by Iranian EFL Learners

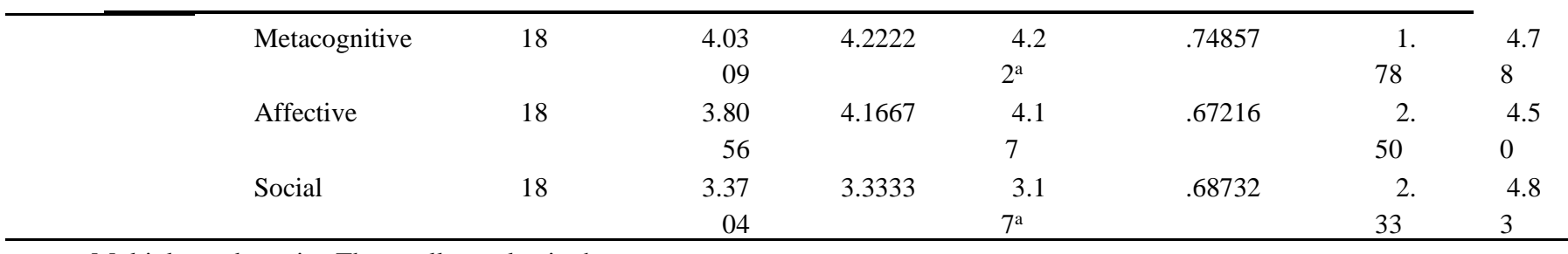

a. Multiple modes exist. The smallest value is shown

As shown in Table 8, it was found that the participants who were low in their levels of WTC, use language learning strategies moderately in general and they prefer to use language learning strategies in the following order; metacognitive, cognitive, social, compensation, memory and affective strategies. Additionally, those participants who were moderate in their level of WTC, preferred to use language learning strategies as metacognitive strategies in the first place, and affective and cognitive strategies in the next places and memory, social and compensation strategies successively and finally those who were in the high level regarding their WTC, use language learning strategies in the following order: metacognitive, affective, cognitive, memory, social and compensation strategy.

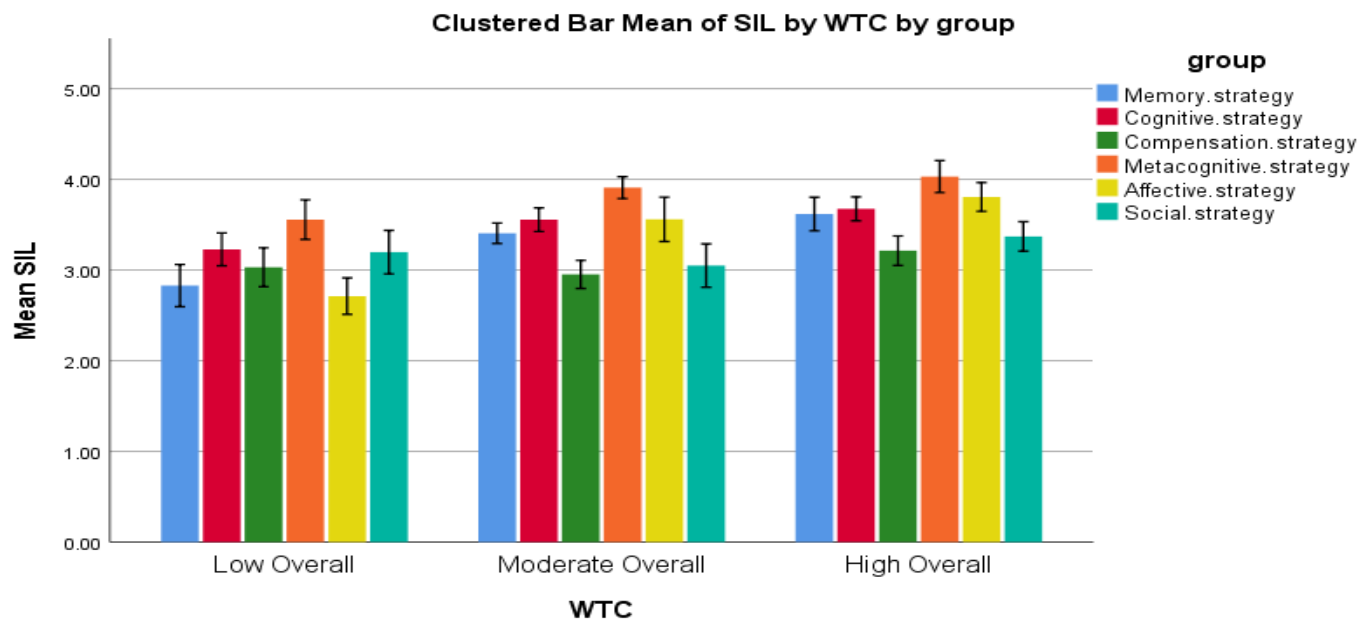

Figure 2. Participants 'preferences in SILL based on levels of WTC

As depicted in Figure 3, the preferences of language learning strategies in regard with WTC are presented. Language learning strategies is shown graphically in details in order to have a better general view.

\subsection{Discussions}

In the previous sections, the analyses of the data which were collected through Strategy Inventory for Language Learning (SILL), as well as willingness to communicate (WTC) questionnaire developed by McCroskey and Richmond were presented and the results were reported in each section. In what follows, the research questions of the study will be answered. Then, the findings are compared with the findings of the past studies in each section.

\subsubsection{Discussion on the first Research question}

As it was mentioned the first research question of the study was as follows: 1. what are Iranian EFL learners' preferences of language learning strategies?

Based on the analysis of the data presented in the previous section in detail, the following answer is provided for the first research question.

Iranian EFL learners prefer to use language learning strategies in the following order: metacognitive, cognitive, affective, memory, social, compensation strategy. 
Furthermore, it was investigated that Iranian EFL learners were generally moderate language learning strategy users. However, a closer look at the data indicated that the participants of the study were strong in the use of metacognitive and cognitive strategies and they used affective, memory, social and compensation strategies moderately.

The results of this part of the study are in line with that of Nikoopour,Farsani, and Neishabouri. (2011) and Zare (2010) who studied the strategies used by EFL learners and indicated that the learners were moderate language learning strategy users. Moreover, according to the present study, EFL learners used metacognitive and cognitive strategies more than other strategies; however, it is in contrast with Y1lmaz's findings (2010) who found that EFL learners employed compensation strategies, as the most frequent language learning strategy. According to Li (2002) compensation strategies help lower the students' anxiety in language learning. However, compensation strategy was the least frequent employed learning strategy by the participants of the present study. The findings of the study are also in line with Tuncer's (2009) findings reporting that bilinguals were more likely to employ cognitive and metacognitive strategies.

\subsubsection{Discussion on the Second Research Question}

The second research question of the study was "What are WTC levels of Iranian EFL learners?"

According to the tabulated data in the analysis section, it was found that the participants were moderate regarding their willingness to communicate. However, a more detailed analysis of the data showed that $23.9 \%$ of the participants were low, $37 \%$ were moderate and $39.1 \%$ were high overall with regard to their levels of willingness to communicate.

\subsubsection{Discussion on the third Research Question}

The third research question of the study was as follows: what is the relationship between Iranian EFL learners' preferences of language learning strategies and their WTC levels? Based on the analysis of the data, it was found that there is a significant relationship between willingness to communicate and the learning strategies of the participants of the study. Additionally, it was found that the participants who were low in their levels of WTC, use language learning strategies moderately in general and they prefer to use language learning strategies in the following order; metacognitive, cognitive, social, compensation, memory and affective strategies. Additionally, those participants who were moderate in their levels of WTC, preferred to use metacognitive strategies in the first place, then affective, cognitive, memory, social and compensation strategies successively. Those who were in the high level regarding their WTC, used language learning strategies in the following order: metacognitive, affective, cognitive, memory, social and compensation strategy. It can be interpreted that the participants at the 3 levels of WTC used metacognitive strategy as the most preferred language learning strategy. Furthermore, it was revealed that the participants in moderate and high levels of WTC used the SILL in the same order although the obtained mean scores were different; higher mean scores for those with high level of WTC.

\section{Conclusions}

The present study investigated Iranian EFL Learners levels of willingness to communicate (WTC) and their preferences of language learning strategies. The results of the study indicated that Iranian EFL learners prefer to use language learning strategies in the following order: metacognitive, cognitive, affective, memory, social, and compensation strategy. A closer look at the data indicated that the participants of the study were strong in the use of metacognitive and cognitive strategies and they used affective, memory, social and compensation strategies moderately. It was also found that the participants were moderate regarding their willingness to communicate. Through a more detailed analysis of the data, they were divided as high, moderate, and low levels of WTC respectively. (37\%) of the participants were found to be willing to communicate moderately, (39.1\%) were highly willing, and $(23.9 \%)$ were low. Teachers and researchers should pay careful attention to see if the reasons for 
low level of WTC are due to language problems such as grammar, vocabulary, pronunciation, and the same, or to other factors (e.g., emotional factors). Furthermore, it was found that there was a significant relationship between willingness to communicate and language learning strategies of the Iranian EFL learners. The participants at the three levels of WTC were, however, moderate strategy users for some of the strategies and strong for some others.

The findings of the current study may be useful to those in the realm of education. It may help language instructors to pay more attention to the strategies language learners employ in the process of language learning. It also can help them to know the extent to which learners are willing to communicate. The results can also help language learners to become aware of their preferences in using SILL and WTC. Another study covering a higher range of population is suggested. Further studies are also suggested addressing the relationship between SILL and different language skills and sub-skills.

\section{References}

[1]Ahmadi, A., \&Mahmoodi, S. (2012). Language learning strategy use and instruction for the Iranian junior high school EFL learners. RALS, 3 (2), 107-134.

[2]Alemi, M., Tajeddin, Z., \&Mesbah, Z. (2013). Willingness to communicate in L2 English: impact of learner variables. Journal of Research in Applied Linguistics, 4(1), 42-61.

[3]Alhaysony, M.(2017). Language learning strategies use by Saudi EFL students: the effect of duration of English language study and gender. TheoryPract. Lang. Stud. 7, 18-28. doi: 10.17507/tpls.0701.03

[4]Aliakbari, M., Kamangar, M., \&Khany, R. (2016).Willingness to Communicate in English among Iranian EFL Students.English Language Teaching, 9(5), 33-44.

[5]Aycan D. A. (2017).The Relationship between EFL Learners' Language Learning Strategy Use, Willingness to Communicate, and L2 Achievement.International Journal of Language AcademyCUELT Special Issue September, 5(5), 78-92.

[6]Bergil, A. S. (2016). The Influence of Willingness to Communicate on Overall Speaking Skills among EFL Learners.Procedia - Social and Behavioral Sciences, 232(2), 177 - 187.

[7]Cao, Y., \& Philip, J. (2006). Interactional context and willingness to communicate: A comparison of behavior in whole class, group and dyadic interaction. System, 34(3), 480-493.

[8]Chamot, A. U. (2004). Issues in language learning strategy research and teaching. Electron. J. Foreign Lang. Teachnol. 1, 14-26

[9]Chen, M. L. (2009). Influence of grade level on perceptual learning style preferences and language learning strategies of Taiwanese English as a foreign language learners. Learning and Individual Differences, 19(2), 304308.

[10]Chen, H. I. (2015). Learner autonomy and the use of language learning strategies in a Taiwanese Junior high school.Journal of Studies in Education, 5(1), 52-64.

[11]Dawadi, S. (2017). Language learning strategies profiles of EFL learners in Nepal. European Journal of Educational and Social Sciences, (Eur. J. Educ. Soc. Sci.) 2, 42-55.

[12]Ersözlü, Z. N. (2010). Determining of the student teachers' learning and studying strategies. Procedia Social and Behavioral Sciences, 2(2), 5147-5151.

[13]Ghavamnia, M., Kassaian, Z., \&Dabaghi, A. (2011). The relationship between language learning strategies, language learning beliefs, motivation, and proficiency: A study of EFL learners in Iran. Journal of Language Teaching and Research, 2(5), 1156-1161.

[14]Fahim, A., \&Dhamotharan, M. (2016).Willingness to Communicate in English among Trainee Teachers in a Malaysian Private University.Journal of Social Sciences, 12(2), 105-112.

[15]Griffiths, C. (2003).Patterns of language learning strategy use. System, 31(3), 367-383.

[16]Hajhashemi, K., Ghombavani, F. and Amirkhiz, Y. (2011). The relationship between EFL high school students' multiple intelligence scores and their use of learning strategies. English Language Teaching, 4(3), 214222.

[17]Hong-Nam, K., \&Leavell, A. G. (2006).Language learning strategy use of ESL students in an intensive English learning context.System, 34(3), 399-415.

[18]Jamaleddin, Z. A. (2015). Comparison between Male and Female in their Willingness to Communicate and Use of Socio-affective Strategies.International Journal of Educational Investigations, 2(4),70-81.

[19]Khajavy, Gh. H., Ghonsooly, B., \&HosseiniFatemi, A. (2016). Willingness to Communicate in English: A Microsystem Model in the Iranian EFL Classroom Context. TESOL QUARTERLY, 50(1), 154-180. 
[20]Kunasaraphan, K. (2015). English learning strategy and proficiency level of the first year students. Procedia - Social and Behavioral Sciences, 197(19), 1853 - 1858.

[21]Li, E. S. (2010). Making suggestions: A contrastive study of young Hong Kong and Australian students.Journal of Pragmatics, 42(3), 598-616.

[22]Mashhady, H., \&Fallah, N. (2014).The relationship between language learning strategies, field of study, gender, and language proficiency.IJRELT, 2(2), 46-61.

[23]McCroskey, J.C. and Baer, J.E.(1985). Willingness to communicate: The construct and its measurement. Proceedings of the Annual Meeting of the Speech Communication Association, Nov. 7-10, Denver, CO.

[24]Mirsane, M., \&Khabiri, M. (2016).The Effect of Teaching Communicative Strategy on EFL Learners' Willingness to Communicate.Theory and Practice in Language Studies, 6(2), 399.

[25]Nikoopour, J., Farsani, M. A., \&Neishabouri, J. K. (2011). Language learning strategy preferences of EFL students.IPEDR, 5, 356-360.

[26]Oxford, R. L. (Ed.). (1996). Language learning strategies around the world: Cross-cultural perspectives. Honolulu: University of Hawaii Press.

[27]Oxford, R. L. (1990). Language learning strategies: What every teacher should know. New York: Newbury House/Harper \& Row.

[28]Oxford, R. L., \&Nyikos, M. (1989).Variables affecting choice of language learning strategies by university students.Modern Language Journal, 73, 291-300.

[29]Rahbar, B., Suzani, M., \&Sajadi, Z. (2016). The relationship between emotional intelligence and willingness to communicate among Iranian intermediate EFL learners. Journal of Language Teaching: Theory and Practice, 2(3), 10-17.

[30]Richards, J.C., Platt J. \& Platt H. (1992). Longman dictionary of language teaching and applied linguistics. Essex: Longman.

[31]Sheorey, R. (1999). An examination of language learning strategy use in the setting of an indigenized variety of English.System, 27(2), 173-190.

[32]Tuncer, U. (2009). How do monolingual and bilingual language learners differ in use of learning strategies while learning a foreign language? Evidence from Mersin University.Procedia-Social and Behavioral Sciences, $1(1), 852-856$.

[33]Valadi, A., Rezaee, A., \&Kogani, P. (2015).The Relationship between Language Learners' Willingness to Communicate and Their Oral Language Proficiency with Regard to Gender Differences.International Journal of Applied Linguistics \& English Literature, 4(5), 147-153.

[34]Yan, D., Chye, L. K., Lin, Z., \& Ying, W. (2010).Research on mother tongue's learning strategies of pupils in Singapore.Procedia Social and Behavioral Science, 2(2), 572- 575.

[35]Yang, N. D. (1999).The relationship between EFL learners' beliefs and learning strategy use.System, 27(4), 515-535.

[36]Y1lmaz, C. (2010). The relationship between language learning strategies, gender, proficiency and selfefficacy beliefs: A study of ELT learners in Turkey. Procedia Social and Behavioral Sciences, 2(2), 682-687.

[37]Yousefi, M., \&Kasaian, S. A. (2014). Relationship between willingness to communicate and Iranian EFL learner's speaking fluency and accuracy. Journal of Advances in English Language Teaching; 2(6), 61-72.

[38]Zare, P. (2010). An investigation into language learning strategy use and gender among undergraduate language learners. World Applied Science Journal, 11(10), 1238-1247.

[39]Zarei, A. A., \&Gilanian, M. (2015).Self-efficacy as a function of language learning. British Journal of Education, Society \&Behavioural Science, 9(3), 223-235. 